\title{
The cost-effectiveness of introducing a vaccine for the prevention of herpes zoster and post-herpetic neuralgia in elderly Danes
}

\author{
LONE BILDE ${ }^{1, *}$ \\ THOMAS T. NIELSEN ${ }^{2}$ \\ FINN RØNHOLT ${ }^{3}$ \\ MARIE KRUSE ${ }^{4}$ \\ ${ }^{1}$ KORA - Danish Institute for Local and Regional Government Research, Denmark \\ ${ }^{2}$ The Danish Health Data Authority, Denmark \\ ${ }^{3}$ Medical Department O, Herlev Hospital, Denmark \\ ${ }^{4}$ Department of Business and Economics, University of Southern Denmark, Denmark
}

\begin{abstract}
Herpes Zoster is an unpleasant and painful skin condition associated with a risk of developing post-herpetic neuralgia if the pain persists. Herpes Zoster most often occurs in elderly people. This study examines the cost-effectiveness of introducing a vaccine against Herpes Zoster in the Danish health care sector. The cost-effectiveness is examined in a Markov lifetime model framework and populated with Danish data and results from the international literature. From the base case analysis, with an ICER of DKK 261,372 per QALY gained, it seems that an implementation of a vaccine against $\mathrm{HZ}$ in the Danish population aged 65 years or more might be cost-effective within generally accepted incremental cost-effectiveness thresholds. Furthermore, an age-specific analysis showed that although the incidence of herpes zoster generally increases with age, targeting the vaccine at persons aged 50-69 years rather than the persons aged 65 years or more, seems to be a more cost-effective strategy from the societal perspective. However, these results are very sensitive to changes in vaccine price, utility values, discount rates, and especially, to the vaccine duration of protection.
\end{abstract}

JEL classification: $\mathrm{I} 1, \mathrm{C} 8, \mathrm{C} 1, \mathrm{D} 6$

Key words: herpes zoster, vaccine, cost-effectiveness, Denmark

\section{Introduction}

Herpes zoster (HZ) or "shingles" is a painful condition affecting especially elderly - and often - frail persons. It results from a sudden reactivation of the varicella zoster virus and is associated with an unpleasant rash and pain which is often severe and disabling. Approximately $25 \%$ of people affected by the varicella zoster virus may develop HZ over their lifetime. In addition, the incidence of $\mathrm{HZ}$ increases with increasing age. Studies from various European countries suggest an annual $\mathrm{HZ}$ incidence of $0.3-0.7 \%$ in the $50-54$ year olds and $0.7-1.27 \%$ in the 80-84 year olds depending on country and type of study (Edmunds et al., 2001, de Melker et al., 2006, Schiffner-Rohe et al., 2010). In Denmark, a survey-

*Correspondence to: Lone Bilde, KORA - Danish Institute for Local and Regional Government Research, Købmagergade 22, DK-1150 Copenhagen K, Denmark. E-mail: lobi@kora.dk

Published: Online December 2016. In print December 2017. dx.doi.org/10.5617/njhe.1792 
based study $(\mathrm{n}=1,207)$ showed cumulative $\mathrm{HZ}$ incidences of $8.9 \%$ (50-65 year olds) and $16 \%$ (age 71 years or more) (Østergaard et al., 2009).

Furthermore, 10-20\% of HZ patients develop post-herpetic neuralgia (PHN). This condition is defined as a persisting pain or pain occurring 1-3 months after the HZ rash onset (Edmunds et al. 2001, Schiffner-Rohe et al., 2010, Gauthier et al., 2009, Gialloreti et al., 2010, Opstelten et al., 2002). HZ can be alleviated by means of antiviral therapy. However, this treatment may not prevent the development of PHN (Oxman et al., 2005).

A large, multicentre, randomized controlled trial (the Shingles Prevention Study (SPS), $\mathrm{N}=38,546$ ) investigated the efficacy of a live attenuated vaccine (Zostavax ${ }^{\circledR}$ ) for the prevention of $\mathrm{HZ}$ and subsequent $\mathrm{PHN}$ in individuals aged 60 and more. With a mean follow-up of 3.12 years, the study found that when comparing the vaccine group to a nonvaccinated group, the incidence of $\mathrm{HZ}$ was reduced by $51.3 \%$ (315 confirmed cases in the vaccine group versus 642 in the placebo group). Furthermore, the primary study end-point, the "burden of illness", a composite end-point based on severity by duration of the total pain and discomfort due to $\mathrm{HZ}$, was reduced by $61.1 \%$. The age-adjusted incidence of PHN following $\mathrm{HZ}$ was reduced by $39 \%$ ( 27 confirmed $\mathrm{HZ}$ cases versus 80 confirmed cases) and the burden of illness due to PHN was reduced by 66.5\%, (Oxman et al., 2005; FDA Package insert, 2011). Also, both the SPS and the subsequent ZEST study in persons aged 50-59 years (Schmader et al., 2012), demonstrated that the vaccine efficacy was highly agedependent, with study participants aged 50-59 years benefitting the most (72\%). Although the incidence of PHN was also lower in the vaccinated study participants, the correlation with age was less clear (CVZ Health Insurance Board, (the Netherlands), University Hospital, A. Gemilli (Italy) 2013). Hence, clinical studies have demonstrated that the vaccine can prevent a sudden reactivation of the varicella zoster virus and reduce the impact and incidence of both $\mathrm{HZ}$ and PHN, considerably.

However, to our knowledge, no cost-effectiveness analysis of introducing the vaccine in Denmark has yet been carried out to inform the local decision-makers. In this paper, therefore, we have estimated the cost-effectiveness of introducing a vaccine for the prevention of $\mathrm{HZ}$ and PHN in the elderly Danish population compared to the current situation without a vaccine. We use Danish data and assumptions, where applicable.

\section{Aim of study}

The first aim of the study is to assess the cost-effectiveness of introducing a vaccine for the prevention of HZ and PHN in Danes aged 65 years or more, compared to the current situation with no vaccination. The second aim of the study is to compare the relative costeffectiveness of vaccinating specific age groups only (e.g. the 50-54 compared to the 55-59 years age group).

The main cost-effectiveness outcomes analysed are the incremental costs per quality-adjusted life year (QALYs) gained and the cost per case of HZ and PHN avoided. The analysis has a societal perspective, but cost-effectiveness and budget impact for the Danish Regions will be reported as well. 


\section{Data and methods}

\subsection{Model presentation}

Cost-effectiveness estimates were generated by simulations of a Markov model. The Markov model used is a Danish adaptation of a generic, Microsoft Excel-based costeffectiveness model developed by Optum Insight. In the model, the population can be analysed as separate 5 year age cohorts (i.e. the 50-54 year old population is first analysed over its lifetime, then the 55-59 year old population etc.), or as a total population. Our base case scenario focuses on the Danish population aged 65 years and older, based on published information on incidence and severity. Furthermore, we analyse the incremental costeffectiveness of vaccinating the 50-54, 55-59, 65-69, 70-74, 75-79, and 80-84 year age groups, respectively.

The model uses monthly cycles to represent the average duration of an episode of HZ, supported by data from the SPS study (Oxman et al., 2005). Within each monthly cycle, a person can stay healthy, get $\mathrm{HZ}$ or die. If she/he gets $\mathrm{HZ}$, the disease comes with four different pain states: no pain, mild, moderate or severe pain. From the HZ state, the person can become healthy, die, or he she/can get PHN, meaning that the pain condition persists beyond the monthly cycle. Once healthy, the patient can get a recurrent $\mathrm{HZ}$, and thus move back into the HZ states. Age-specific mortality rates were applied to each health state to determine the monthly probability of transitioning to death.

Figure 1 below provides an overview of the model structure and health states.

Figure 1: Markov model structure and health states

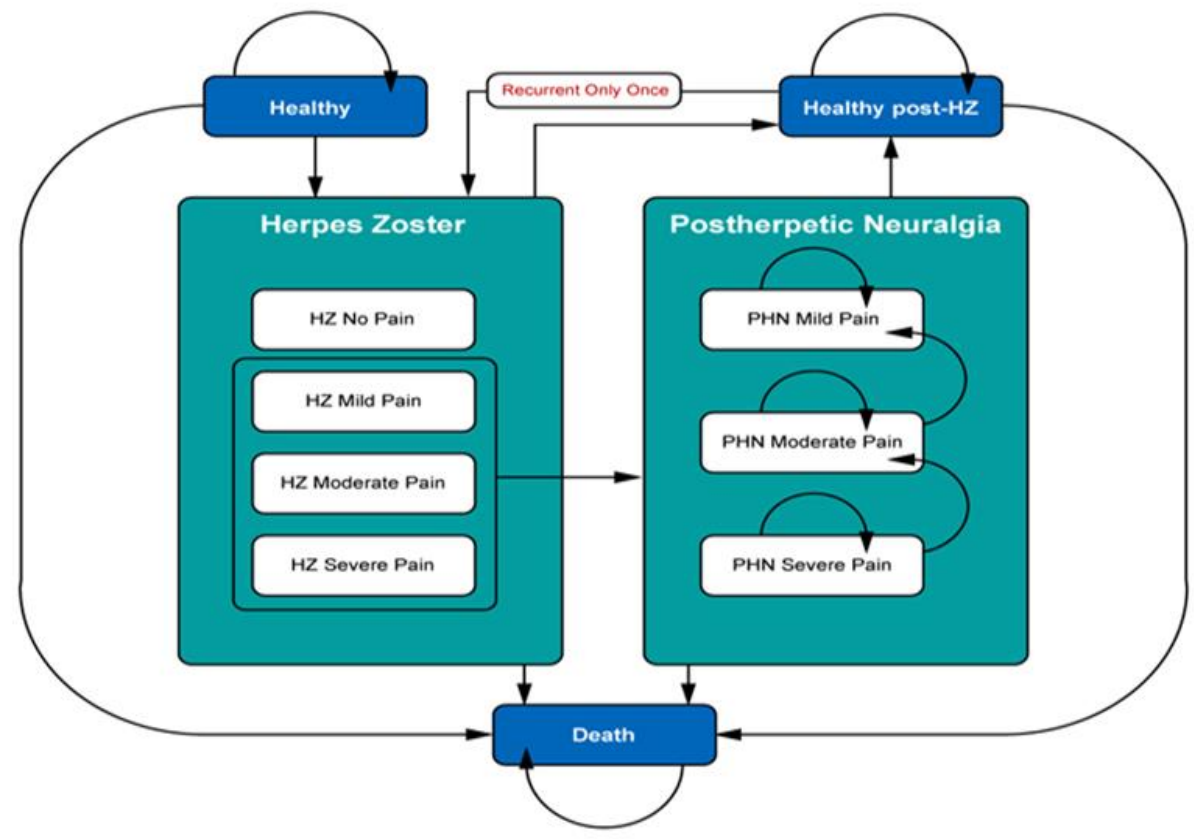

\subsection{Model assumptions and input parameters}

To populate the model, we used inputs derived from several sources. The epidemiology of the Danish population (mortality, age and gender composition) is well documented and was collected from Statistics Denmark (Table 1). As to the epidemiology of HZ, we only found one Danish study on the lifetime cumulative HZ incidence (Østergaard et al., 2009) from which annual incidences by age groups could not be calculated. Therefore, the annual 
incidence of $\mathrm{HZ}$ and $\mathrm{PHN}$ in different age groups was retrieved as a mean of six studies from other European countries (Edmunds et al., 2001, de Melker et al., 2006, SchiffnerRohe et al., 2010, Gauthier et al., 2009, Gialloretti et al., 2010; Opstelten et al., 2002).

Table 1: Epidemiology of herpes zoster

\begin{tabular}{|c|c|c|c|c|c|}
\hline \multicolumn{6}{|c|}{ Incidence } \\
\hline Age & \multicolumn{2}{|c|}{$\begin{array}{l}\text { Mean annual incidence } \\
\text { of Herpes Zoster (per } \\
10,000 \text { persons) }\end{array}$} & \multicolumn{2}{|c|}{$\begin{array}{l}\text { PHN per Herpes } \\
\text { Zoster episode }\end{array}$} & Source \\
\hline $50-54$ & \multicolumn{2}{|l|}{42.5} & \multicolumn{2}{|l|}{$9.03 \%$} & \multirow{2}{*}{$\begin{array}{l}\mathrm{HZ} \text { incidence found as the mean of the } \\
\text { incidences reported in (Edmunds }\end{array}$} \\
\hline $55-59$ & \multicolumn{2}{|l|}{49.7} & \multicolumn{2}{|l|}{$10.22 \%$} & \\
\hline $60-64$ & \multicolumn{2}{|l|}{62.7} & \multicolumn{2}{|l|}{$13.98 \%$} & \multirow{3}{*}{$\begin{array}{l}\text { 2001, de Melker 2006, Schiffner-Rohe } \\
\text { 2010, Gauthier 2009, Gialoretti 2010, } \\
\text { Opstelten 2009) }\end{array}$} \\
\hline $65-69$ & \multicolumn{2}{|l|}{64.9} & \multicolumn{2}{|l|}{$16.58 \%$} & \\
\hline $70-74$ & \multicolumn{2}{|l|}{77.7} & \multicolumn{2}{|l|}{$19.41 \%$} & \\
\hline $75-79$ & \multicolumn{2}{|l|}{86.1} & \multicolumn{2}{|l|}{$22.07 \%$} & \multirow{5}{*}{$\begin{array}{l}\text { PHN incidence found as the mean of } \\
\text { the PHN proportions reported in (see } \\
\text { above) }\end{array}$} \\
\hline $80-84$ & \multirow{2}{*}{\multicolumn{2}{|c|}{$\begin{array}{l}92.8 \\
97.6\end{array}$}} & \multicolumn{2}{|l|}{$24.67 \%$} & \\
\hline $85-89$ & & & $23.79 \%$ & & \\
\hline $90-94$ & \multicolumn{2}{|l|}{105.4} & \multicolumn{2}{|l|}{$23.79 \%$} & \\
\hline $95+$ & \multicolumn{2}{|l|}{105.4} & \multicolumn{2}{|l|}{$23.79 \%$} & \\
\hline \multicolumn{6}{|c|}{ Mean duration of episodes } \\
\hline \multicolumn{3}{|c|}{ Herpes Zoster } & \multicolumn{2}{|l|}{ PHN } & Source \\
\hline \multicolumn{3}{|c|}{1 month } & \multicolumn{2}{|l|}{9 months } & $($ Chidiac 2001) \\
\hline \multicolumn{6}{|c|}{ Gender split } \\
\hline \multicolumn{3}{|c|}{ Female proportion of $\mathrm{HZ}$ cases } & $\begin{array}{l}\text { Female pro } \\
\text { PHN cases }\end{array}$ & ortion of & Source \\
\hline $62 \%$ & & & $62 \%$ & & (Sanofi Pasteur MSD 2009) \\
\hline Pain $s$ & & & & & \\
\hline Herpes & & & & & \\
\hline Age & None & Mild & Moderate & Severe & Source \\
\hline $50-69$ & $27 \%$ & $41 \%$ & $18 \%$ & $14 \%$ & (Oxman 2005) \\
\hline $70+$ & $26 \%$ & $32 \%$ & $23 \%$ & $19 \%$ & (Uxman 2005) \\
\hline PHN & & & & & \\
\hline Age & Mild & Moderate & Severe & & Source \\
\hline $50-69$ & $42 \%$ & $9 \%$ & $49 \%$ & & $(0 x m a n$ 2005) \\
\hline $70+$ & $17 \%$ & $16 \%$ & $67 \%$ & & (Uxman 2005) \\
\hline
\end{tabular}

According to a systematic literature review of population-based studies of $\mathrm{HZ}$ incidence in the EU, Iceland and Norway (Pinchinat et al., 2013), the HZ incidence does not differ significantly across European countries. Therefore, we believe the studies provide a suitable approximation of the HZ incidence in Denmark. The HZ incidence increases with age, from $43 \mathrm{HZ}$ cases per 10,000 persons between 50 and 54 years old, to 105 cases per 10,000 persons 90 years old or older.

Healthcare resource use and unit costs (Table 2) were collected from local sources: The rate of admission to hospital (day case or in-patient care), length, type, and cost of hospital care were calculated using data from the National Cost Database. 
Table 2: Health care resource utilisation and costs

\begin{tabular}{|c|c|c|c|}
\hline \multicolumn{4}{|c|}{ Parameter } \\
\hline \multicolumn{4}{|c|}{ Hospital care } \\
\hline \multicolumn{3}{|c|}{$\begin{array}{l}\text { Percentage with at least one } \\
\text { episode of hospital care }\end{array}$} & $\begin{array}{l}\text { Own calculations based on data from the Danish Health } \\
\text { and Medicines Authority, population data from Statistics }\end{array}$ \\
\hline \multirow[t]{8}{*}{ Age } & $50-54$ & 3.52 & Denmark, and our HZ incidence estimate. \\
\hline & $55-59$ & 6.02 & \\
\hline & $60-64$ & 5.28 & This covers both day cases and in-patient admissions to \\
\hline & $65-69$ & 8.07 & hospital. \\
\hline & $70-74$ & 4.91 & \\
\hline & $75-79$ & 8.68 & \\
\hline & $80-84$ & 6.10 & \\
\hline & $85+$ & 10.91 & \\
\hline Cost & Imission (in DKK) & $8,693.58$ & \\
\hline \multicolumn{4}{|c|}{ Primary care contacts and costs } \\
\hline \multicolumn{3}{|c|}{ Mean number of GP visits } & (Sanofi Pasteur MSD 2010, DADL 2012) \\
\hline & No pain & 1.50 & \\
\hline & Mild pain & 1.40 & \\
\hline & Moderate pain & 1.90 & \\
\hline & Severe pain & 2.70 & \\
\hline \multicolumn{4}{|c|}{ Mean number of GP home visits } \\
\hline \multicolumn{4}{|c|}{$\begin{array}{l}\text { Mean number of GP telephone } \\
\text { contacts }\end{array}$} \\
\hline \multicolumn{4}{|c|}{ Costs per patient (in DKK) } \\
\hline & No pain & 211.25 & \\
\hline & Mild pain & 198.30 & \\
\hline & Moderate pain & 263.06 & \\
\hline & Severe pain & 366.68 & \\
\hline \multicolumn{4}{|c|}{ Out-patient specialist visits and costs } \\
\hline Mea & ber of specialist visits & & (Sanofi Pasteur MSD 2010, DADL 2012) \\
\hline & No pain & 0.10 & \\
\hline & Mild pain & 0.14 & \\
\hline & Moderate pain & 0.14 & \\
\hline & Severe pain & 0.14 & \\
\hline \multicolumn{4}{|c|}{ Costs per patient (in DKK) } \\
\hline & No pain & 28.68 & \\
\hline & Mild pain & 63.35 & \\
\hline & Moderate pain & 63.35 & \\
\hline & Severe pain & 63.35 & \\
\hline \multicolumn{4}{|c|}{ Medication } \\
\hline $\begin{array}{l}\text { Mon } \\
\text { medi }\end{array}$ & $\begin{array}{l}\text { st prescribed } \\
\text { (in } \mathrm{DKK} \text { ) }\end{array}$ & & $\begin{array}{l}\text { (Sanofi Pasteur MSD 2010, DADL 2012, Danish Health } \\
\text { and Medicines Authority 2013) }\end{array}$ \\
\hline \multicolumn{4}{|c|}{ Herpes zoster } \\
\hline & No pain & 139.46 & \\
\hline & Mild pain & 185.55 & \\
\hline & Moderate pain & 185.55 & \\
\hline & Severe pain & 185.55 & \\
\hline \multicolumn{4}{|c|}{ PHN } \\
\hline & Mild pain & 49.37 & \\
\hline & Moderate pain & 49.37 & \\
\hline & Severe pain & 49.37 & \\
\hline \multicolumn{4}{|c|}{ Diagnostic tests } \\
\hline $\begin{array}{l}\text { Prop } \\
\text { (perc }\end{array}$ & of patients with tests & 12.00 & (Sanofi Pasteur MSD 2010, DADL 2012) \\
\hline Cost & ts (in DKK) & 688.69 & \\
\hline Cost & tient (in DKK) & 80.58 & \\
\hline
\end{tabular}


This database contains patient-level hospitalisation data - procedure and diagnosisspecific, and DRG-cost data derived from data from all hospitals using a step-down cost accounting method (Ankjær-Jensen et al., 2006). From the National Cost Database, we calculated a hospital admission rate and weighted the average admission and cost figures for all patients admitted to hospital (both in-patients, emergency visits, and day cases) with a HZ ICD 10 diagnosis over two years (2008 and 2009). This resulted in a mean cost per episode of hospital care of DKK 8,694 (2011-prices). The rate of hospital admission generally increases with age; 11 per cent of HZ-patients aged 85 or more are treated at a hospital, while the corresponding number for HZ-patients between 50 and 54 years of age is only 4 per cent.

Data from an unpublished prospective study (Sanofi Pasteur MSD, 2009) on Danish $\mathrm{HZ}$ patients in general practice $(\mathrm{N}=489)$ provided estimates of the use and type of visits to general practitioners and other primary care providers, visits to out-patient specialists, the use of medication, and the number of diagnostic tests per HZ/PHN episode (see Table 2). Results from this study were comparable to the data used from other sources, e.g. assumptions about the incidence of PHN, and the days of absence from work for $\mathrm{HZ}$ patients. The resource use was multiplied by unit costs based on fees negotiated between the Regions and the primary care providers, and the price per dose of medicines from the Danish Medicines Agency.

It is assumed - in line with clinical practice in Denmark - that all HZ-patients visit a general practitioner (GP). The monthly number of GP-visits increases with pain severity. The average HZ-patient with no pain visits the GP 1.5 times per month, while the average HZ-patient with severe pain visits the GP 2.7 times per month (Sanofi Pasteur MSD, 2009, DADL, 2012). Monthly medication costs are highest for HZ-patients with some pain, since they are most likely to be treated with both antiviral and pain medication, while PHNpatients are generally not treated with antiviral medication. Likewise, HZ-patients with no pain do generally not receive pain medication.

Vaccine efficacy assumptions were based on the age-specific mean reductions of the incidence of $\mathrm{HZ}$ and PHN found in the clinical trials, SPS and ZEST, described by Oxman et al., (2005) and Schmader et al., (2012), and by the FDA (FDA Package insert, 2011). The SPS study found a mean $\mathrm{HZ}$ incidence reduction of $64 \%$ in the vaccinated 65-69 years age group compared to the control group, $41 \%$ reduction in the 70-79 years age group, and a reduction of $18 \%$ in the persons aged 80 years or more. Vaccine efficacy assumptions regarding the proportion of HZ patients who develop PHN were also from the SPS study. This study reported a mean reduction of 5\% in the vaccinated 65-69 years age group, a 55\% reduction in the 70-79 years age group, and a $26 \%$ reduction in persons aged 80 years or more. The reduction in the duration of PHN was calculated as the difference in months in the vaccinated versus the placebo group (6.1 versus 8.3 months in the 50-69 years group, and 7.6 versus 10.9 in the 70-79 years group.) Similarly, efficacy assumptions regarding the age groups of 50-54 and 55-59 years were derived from the ZEST study (Schmader et al., 2012), which reported a reduction of the incidence of $\mathrm{HZ}$ with vaccination of $69.8 \%$ among 50-59 year olds. Since this analysis provides 5-year age groups, we assumed the same incidence as for the 10-year age group provided by the ZEST study. The primary end-point in the SPS and the ZEST studies was the burden of illness due to HZ. This is a severity-byduration measure of the total pain and discomfort associated with HZ. For each confirmed case of HZ, responses to the "worst pain" question in the Zoster Brief Pain Inventory were used to calculate a HZ-related severity-of-illness score defined as the area under the curve (AUC) of HZ plotted against time during the 182-day period after the onset of the rash. The HZ "burden of illness" score represented the average severity of illness among all subjects in the vaccine or placebo groups: it was calculated as the sum of the HZ severity of illness 
scores. These data (Oxman et al., 2005, Schmader et al., 2012) were used in the model to reflect the split of $\mathrm{HZ}$ patients into four different stages of pain (none, mild, moderate, severe), and the length of stay in each state (1,2,3,4 months etc.) for each of the 5-year age bands, converted into model transition probabilities.

Table 3: Vaccine efficacy

\begin{tabular}{|c|c|c|c|c|c|c|c|}
\hline \multicolumn{8}{|c|}{ Efficacy of Zostavax on $\mathrm{HZ}$ incidence compared with placebo } \\
\hline \multirow{2}{*}{$\begin{array}{l}\text { Age } \\
\text { group } \\
\text { (years) }\end{array}$} & \multicolumn{3}{|l|}{ Zostavax } & \multicolumn{4}{|l|}{ Placebo } \\
\hline & $\begin{array}{l}\text { No. of } \\
\text { subjects }\end{array}$ & $\begin{array}{l}\text { No. of } \\
\text { HZ } \\
\text { cases }\end{array}$ & $\begin{array}{l}\text { Incidence } \\
\text { rate of } \mathrm{HZ} \\
\text { per } 1,000 \\
\text { person-years }\end{array}$ & $\begin{array}{l}\text { No. of } \\
\text { subjects }\end{array}$ & $\begin{array}{l}\text { No. of } \\
\text { HZ } \\
\text { cases }\end{array}$ & $\begin{array}{l}\text { Incidence rate } \\
\text { of } \mathrm{HZ} \text { per } 1,000 \\
\text { person-years }\end{array}$ & $\begin{array}{l}\text { Vaccine efficacy } \\
(95 \% \mathrm{CI})\end{array}$ \\
\hline Overall & 19,254 & 315 & 27 & 19,247 & 642 & 11.1 & $51 \%(44 \%, 58 \%)$ \\
\hline $60-69$ & 10,370 & 122 & 3.9 & 10,356 & 334 & 10.8 & $64 \%(56 \%, 71 \%)$ \\
\hline $70-79$ & 7,621 & 156 & 6.7 & 7,559 & 261 & 11.4 & $41 \%(28 \%, 52 \%)$ \\
\hline$\geq 80$ & 1,263 & 37 & 9.9 & 1,332 & 47 & 12.2 & $18 \%(-29 \%, 48 \%)$ \\
\hline
\end{tabular}

Source (Oxman et al., 2005 in FDA package, 2011)

\begin{tabular}{|c|c|c|c|c|c|c|c|}
\hline \multicolumn{8}{|c|}{ Efficacy of Zostavax on $\mathrm{HZ}$ incidence compared with placebo from the ZEST study } \\
\hline \multirow{2}{*}{$\begin{array}{l}\text { Age } \\
\text { group } \\
\text { (years) }\end{array}$} & \multicolumn{3}{|l|}{ Zostavax } & \multicolumn{4}{|l|}{ Placebo } \\
\hline & $\begin{array}{l}\text { No. of } \\
\text { subjects }\end{array}$ & $\begin{array}{l}\text { No. } \\
\text { of } \\
\text { HZ } \\
\text { cases }\end{array}$ & $\begin{array}{l}\text { Incidence rate } \\
\text { of } \mathrm{HZ} \text { per } \\
1,000 \text { person- } \\
\text { years }\end{array}$ & $\begin{array}{l}\text { No. of } \\
\text { subjects }\end{array}$ & $\begin{array}{l}\text { No. of } \\
\text { HZ } \\
\text { cases }\end{array}$ & $\begin{array}{l}\text { Incidence rate of } \\
\text { PHN per } 1,000 \\
\text { person-years }\end{array}$ & $\begin{array}{l}\text { Vaccine efficacy } \\
(95 \% \mathrm{CI})\end{array}$ \\
\hline 50-59 & 11,211 & 30 & 1,994 & 11,228 & 99 & 6,558 & $\begin{array}{l}69.8 \% \\
(54.1 \%, 80.6 \%)\end{array}$ \\
\hline
\end{tabular}

Source: (Schmader et al., 2012 in FDA package, 2011)

\begin{tabular}{|l|l|l|l|l|l|l|l|l|l|}
\hline \multicolumn{7}{|l|}{ Postherpetic Neuralgia (PHN) in the Shingles Prevention Study } \\
\hline $\begin{array}{l}\text { Age } \\
\text { group } \\
\text { (years) }\end{array}$ & \begin{tabular}{l} 
Zostavax \\
\cline { 2 - 10 } \\
subjects
\end{tabular} & $\begin{array}{l}\text { No. } \\
\text { of } \\
\text { HZ } \\
\text { cases }\end{array}$ & $\begin{array}{l}\text { Incidence } \\
\text { rate of } \\
\text { HZ per } \\
1,000 \\
\text { person- } \\
\text { years }\end{array}$ & $\begin{array}{l}\% \text { HZ } \\
\text { cases } \\
\text { with } \\
\text { PHN }\end{array}$ & $\begin{array}{l}\text { No. of } \\
\text { subjects }\end{array}$ & $\begin{array}{l}\text { No. } \\
\text { of } \\
\text { HZ } \\
\text { cases }\end{array}$ & $\begin{array}{l}\text { No. } \\
\text { of } \\
\text { PHN } \\
\text { cases }\end{array}$ & $\begin{array}{l}\text { Incidence } \\
\text { rate of } \\
\text { PHN per } \\
1,000 \\
\text { person- } \\
\text { years }\end{array}$ & $\begin{array}{l}\text { Vaccine } \\
\text { efficacy against } \\
\text { PHN in subjects } \\
\text { who develop } \\
\text { HZ post- } \\
\text { vaccination } \\
(95 \% \text { CI) }\end{array}$ \\
\hline Overall & 19,254 & 315 & 27 & $8.6 \%$ & 19,247 & 642 & 80 & 80 & $\begin{array}{l}39 \% \\
(7 \%, 59 \%)\end{array}$ \\
\hline $60-69$ & 10,370 & 122 & 8 & $6.6 \%$ & 10,356 & 334 & 23 & 23 & $\begin{array}{l}5 \% \\
(-107 \%-56 \%)\end{array}$ \\
\hline $70-79$ & 7,621 & 156 & 12 & $7.7 \%$ & 7,559 & 261 & 45 & 45 & $\begin{array}{l}55 \% \\
(18 \%-76 \%)\end{array}$ \\
\hline$\geq 80$ & 1,263 & 37 & 7 & $18.9 \%$ & 1,332 & 47 & 12 & 12 & $\begin{array}{l}26 \% \\
(-69 \%-68 \%)\end{array}$ \\
\hline
\end{tabular}

Source (Oxman et al., 2005 in FDA package 2011) 
Table 4: Base case assumptions (efficacy, coverage rate, utility values, vaccine costs)

\begin{tabular}{|c|c|c|c|}
\hline \multicolumn{4}{|c|}{ Vaccine efficacy assumptions in model (reduction of $\mathrm{HZ}$ incidence) } \\
\hline & PHN & \multirow[b]{2}{*}{ Source } \\
\hline Age (years) & Mean & & \\
\hline $50-54$ & $70.0 \%$ & $0.0 \%$ & (FDA package, 2011, Schmader et al., 2012) \\
\hline $55-59$ & $70.0 \%$ & $0.0 \%$ & \\
\hline $60-64$ & $64.0 \%$ & $5.0 \%$ & \\
\hline $65-69$ & $64.0 \%$ & $5.0 \%$ & \\
\hline $70-74$ & $41.0 \%$ & $55.0 \%$ & \\
\hline $75-79$ & $41.0 \%$ & $55.0 \%$ & \\
\hline $80-84$ & $18.0 \%$ & $26.0 \%$ & \\
\hline $85-89$ & $18.0 \%$ & $26.0 \%$ & \\
\hline $90-94$ & $18.0 \%$ & $26.0 \%$ & \\
\hline $95-99$ & $18.0 \%$ & $26.0 \%$ & \\
\hline 100 & $18.0 \%$ & $26.0 \%$ & \\
\hline
\end{tabular}

Coverage rate

Source

\begin{tabular}{|c|c|c|}
\hline \multirow{2}{*}{\multicolumn{3}{|c|}{$\begin{array}{l}11 \% \\
\text { Vaccine duration }\end{array}$}} \\
\hline & & \\
\hline $\begin{array}{l}\text { Lifetime with an annual } \\
\text { waning rate of } 8.3 \%\end{array}$ & \multicolumn{2}{|r|}{ (Pelissier 2007, de Boer 2013) } \\
\hline Utility values & \multicolumn{2}{|r|}{ (Oster 2005) } \\
\hline Herpes zoster & & \multirow{9}{*}{ (Oster 2005 and 2006, Brisson 2008) } \\
\hline No pain & 0.864 & \\
\hline Mild & 0.712 & \\
\hline Moderate & 0.603 & \\
\hline Severe & 0.254 & \\
\hline Post-herpetic Neuralgia & & \\
\hline Mild & 0.712 & \\
\hline Moderate & 0.603 & \\
\hline Severe & 0.254 & \\
\hline \multicolumn{3}{|l|}{ Vaccine costs } \\
\hline Unit cost & Administration cos & Source \\
\hline
\end{tabular}

A natural upper bound on the vaccine coverage rate was provided by the influenza vaccine coverage rate in Denmark, which is currently 45-50\% of persons aged 60 and older (Statens Serum Institut, 2013). As we cannot expect the same coverage rate as for the flu vaccine, we settled on a conservative coverage rate of $11 \%$ (Moore et al., 2010). However, it is important to note that the coverage rate has no bearing on the incremental costeffectiveness results.

Also, we assumed that the effect of the vaccine has an annual waning rate of $8.3 \%$ (Pellisier et al., 2010, de Boer et al., 2013), meaning that protection of the vaccine is assumed to gradually decrease over the vaccinated person's lifetime.

In the base case scenario, the vaccine price was assumed to be DKK 1,345, based on information from the manufacturer. The vaccine administration price was $132 \mathrm{DKK}$, based on the fee charged by general practitioners for vaccination against flu (DADL 2012).

Productivity losses for employed people below 67 years of age were assumed to be of the same magnitude as the recent UK study (Moore et al., 2010), according to which an event of HZ with no pain results in 8.8 days off work, a case with mild pain results in 9.6 days off work, moderate and severe pain states 12.3 and 21 days, respectively. An event of PHN results in a mean productivity cost of 8.8 days for a case of mild pain, 31.5 days for a case of moderate pain, and 70.5 days for a case of severe pain. Assumptions on the value of 
work days lost were based on data on mean income, rate of employment, and social costs from Statistics Denmark (www.statistikbanken.dk).

In the model, utility weights used to estimate QALYs were applied to different HZ and PHN pain states. In practice, disease-specific decrements were applied to age-specific utilities to obtain the final utility value. Base case utility losses associated with $\mathrm{HZ}$ and PHN were derived from an observational study involving 385 patients aged $\geq 65$ years reported by Oster et al. (2005). PHN utility weights were determined using the EQ-5D questionnaire. Results from this study were also used to assess HZ-related pain states, since the utility associated with the different levels of pain severity does not vary between the various causes of neuropathic pain. This is supported by a publication from McDermott et al. (2006) who investigated the quality of life in neuropathic pain patients in five European countries reporting utility weights by severity. These weights - and the weights used in another costeffectiveness model (van Hoek et al., 2009) are very similar to the ones reported by Oster et al. (2005), indicating that the latter are appropriate to use in this model. The baseline utility corresponding to the health state 'no pain' was derived from data collected in the SPS study using a pain visual analogue scale (Bresse et al., 2013, Oster et al., 2005). For the agespecific health-related quality of life of the Danish background population without $\mathrm{HZ}$ or PHN, we used the QALY weights from a Danish population study based on EQ-5D (Olsen and Jepsen, 2010, Sørensen and Gudex, 2009).

Finally, a discount rate of $3 \%$ was assumed in the base case in accordance with other Danish cost-effectiveness studies.

In the base case analysis, the Markov model was run for the population of 65 years of age or more based on the base case assumptions described in Table 1-4. In addition, analyses were run for different age groups, starting from the persons aged 50 to 54 years and ending with the persons aged 80 to 84 years.

The sensitivity of assumptions was tested using both a deterministic sensitivity analysis and a probabilistic sensitivity analysis.

In the deterministic analysis, base case assumptions were allowed to vary one at a time over a range, resulting in a set of ranges of results. The results were reported in a tornado diagram, showing the impact of the parameters on the results. The assumptions regarding high and low estimates for the sensitivity analysis were reported in Table 5.

Table 5: Deterministic sensitivity analysis

\begin{tabular}{lccc}
\hline \multicolumn{2}{l}{ Alternative incidence - compared to base case } & & \\
Age & $\begin{array}{l}\text { Mean annual incidence of } \\
\text { Herpes Zoster }\end{array}$ & $\begin{array}{c}\text { PHN per } \\
\text { (per 10,000 persons) }\end{array}$ & Source \\
\hline $50-54$ & 42.0 & $7.4 \%$ & (Edmunds 2001) \\
$55-59$ & 52.1 & $7.4 \%$ & \\
$60-64$ & 59.2 & $21.2 \%$ & \\
$65-69$ & 67.0 & $21.2 \%$ & \\
$70-74$ & 75.3 & $28.6 \%$ & \\
$75-79$ & 84.2 & $28.6 \%$ & \\
$80-84$ & 93.7 & $34.4 \%$ & \\
$85-89$ & 115.8 & $34.4 \%$ & \\
$90-94$ & 115.8 & $34.4 \%$ & \\
$95+$ & 115.8 & $34.4 \%$ & \\
\hline
\end{tabular}


Table 5 continued

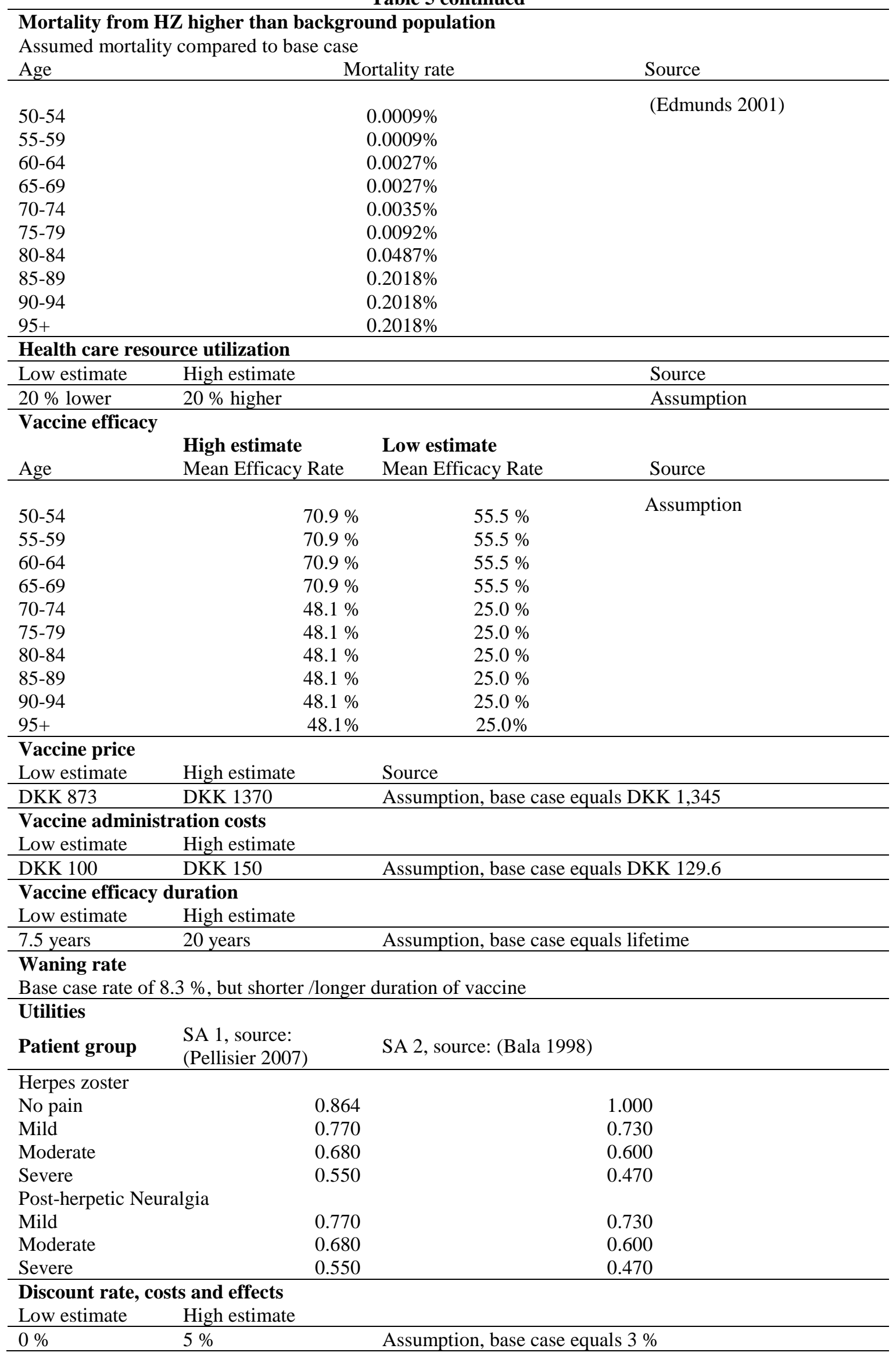


In the probabilistic sensitivity analysis, all assumptions were allowed to vary simultaneously along a distribution, while the cost-effectiveness model was simulated 1,000 times. The result of the probabilistic sensitivity analysis was reported as a plane of results and an interval which the ICER falls into with a probability of 95 percent (Drummond et al., 2005). In addition, the probability of the vaccine being cost-effective was reported for a range of societal willingness to pay amounts per QALY (Stinnett and Mullahy, 1998). The parameters used are presented below in Table 6 .

Table 6: Parameters for probabilistic sensitivity analysis

\begin{tabular}{|c|c|c|c|c|c|c|}
\hline \multicolumn{2}{|l|}{ Parameter } & \multirow{2}{*}{$\begin{array}{c}\text { Base case } \\
70.00 \%\end{array}$} & \multirow{2}{*}{$\begin{array}{l}\begin{array}{l}\text { Distribution } \\
\text { type }\end{array} \\
\text { Lognormal }\end{array}$} & \multicolumn{2}{|c|}{$\mathbf{A}$} & $\beta$ Sources \\
\hline \multirow{11}{*}{$\begin{array}{l}\text { HZ Vaccine } \\
\text { efficacy }\end{array}$} & $50-54$ & & & -1.20 & 0.23 & ZEST (CVZ 2013) \\
\hline & $55-59$ & $70.00 \%$ & Lognormal & -1.20 & 0.23 & ZEST \\
\hline & $60-64$ & $64.00 \%$ & Lognormal & -1.02 & 0.11 & FDA (Schmader, Oxman) \\
\hline & $65-69$ & $64.00 \%$ & Lognormal & -1.02 & 0.11 & FDA \\
\hline & $70-74$ & $41.00 \%$ & Lognormal & -0.53 & 0.10 & FDA \\
\hline & $75-79$ & $41.00 \%$ & Lognormal & -0.53 & 0.10 & FDA \\
\hline & $80-84$ & $18.00 \%$ & Lognormal & -0.20 & 0.23 & FDA \\
\hline & $85-89$ & $18.00 \%$ & Lognormal & -0.20 & 0.23 & FDA \\
\hline & $90-94$ & $18.00 \%$ & Lognormal & -0.20 & 0.23 & FDA \\
\hline & $95-99$ & $18.00 \%$ & Lognormal & -0.20 & 0.23 & FDA \\
\hline & 100 & $18.00 \%$ & Lognormal & -0.20 & 0.23 & FDA \\
\hline $\begin{array}{l}\text { Vaccine } \\
\text { duration }\end{array}$ & $\begin{array}{l}\text { Yearly waning } \\
\text { rate }\end{array}$ & $8.31 \%$ & Uniform & $0 \%$ & $8.31 \%$ & Pelissier (2007) \\
\hline \multirow{4}{*}{$\begin{array}{l}\text { HZ primary care } \\
\text { costs }\end{array}$} & No pain & 211 & Gamma & 96.04 & 2.20 & ZAP Pro study (SPMSD) \\
\hline & Mild pain & 198 & Gamma & 96.04 & 2.06 & \\
\hline & Moderate pain & 263 & Gamma & 96.04 & 2.74 & \\
\hline & Severe pain & 367 & Gamma & 96.04 & 3.82 & \\
\hline \multirow{3}{*}{$\begin{array}{l}\text { PHN primary } \\
\text { care costs }\end{array}$} & Mild pain & 198 & Gamma & 96.04 & 2.06 & Zest /FDA (see above) \\
\hline & Moderate pain & 263 & Gamma & 96.04 & 2.74 & \\
\hline & Severe pain & 367 & Gamma & 96.04 & 3.82 & \\
\hline \multirow{3}{*}{$\begin{array}{l}\text { HZ/PHN utility } \\
\text { decrements }\end{array}$} & Mild & 0.70 & Beta & 1,951 & 826 & Oster (2005 and 2006) \\
\hline & Moderate & 0.58 & Beta & 742 & 543 & Oster \\
\hline & Severe & 0.26 & Beta & 195 & 566 & Oster \\
\hline \multirow{11}{*}{$\begin{array}{l}\text { HZ incidence } \\
\text { (monthly) }\end{array}$} & $50-54$ & $0.04 \%$ & Gamma & 96.036 & 0.000004 & European studies \\
\hline & $55-59$ & $0.04 \%$ & Gamma & 96.036 & 0.000004 & European studies \\
\hline & $60-64$ & $0.05 \%$ & Gamma & 96.036 & 0.000005 & European studies \\
\hline & $65-69$ & $0.05 \%$ & Gamma & 96.036 & 0.000006 & European studies \\
\hline & $70-74$ & $0.07 \%$ & Gamma & 96.036 & 0.000007 & European studies \\
\hline & $75-79$ & $0.07 \%$ & Gamma & 96.036 & 0.000008 & European studies \\
\hline & $80-84$ & $0.08 \%$ & Gamma & 96.036 & 0.000008 & European studies \\
\hline & $85-89$ & $0.08 \%$ & Gamma & 96.036 & 0.000008 & European studies \\
\hline & $90-94$ & $0.08 \%$ & Gamma & 96.036 & 0.000094 & European studies \\
\hline & $95-99$ & $0.09 \%$ & Gamma & 96.036 & 0.000009 & European studies \\
\hline & 100 & $0.09 \%$ & Gamma & 96.036 & 0.000009 & European studies \\
\hline \multirow{11}{*}{ PHN incidence } & $50-54$ & $9.03 \%$ & Gamma & 96.036 & 0.000941 & European studies \\
\hline & $55-59$ & $10.22 \%$ & Gamma & 96.036 & 0.001064 & European studies \\
\hline & $60-64$ & $13.98 \%$ & Gamma & 96.036 & 0.001456 & European studies \\
\hline & $65-69$ & $16.58 \%$ & Gamma & 96.036 & 0.001727 & European studies \\
\hline & $70-74$ & $19.41 \%$ & Gamma & 96.036 & 0.002021 & European studies \\
\hline & $75-79$ & $22.07 \%$ & Gamma & 96.036 & 0.002298 & European studies \\
\hline & $80-84$ & $24.67 \%$ & Gamma & 96.036 & 0.002569 & European studies \\
\hline & $85-89$ & $23.79 \%$ & Gamma & 96.036 & 0.002477 & European studies \\
\hline & $90-94$ & $23.79 \%$ & Gamma & 96.036 & 0.002477 & European studies \\
\hline & $95-99$ & $23.79 \%$ & Gamma & 96.036 & 0.002477 & European studies \\
\hline & 100 & $23.79 \%$ & Gamma & 96.036 & 0.002477 & European studies \\
\hline
\end{tabular}


Table 6 continued

\begin{tabular}{|c|c|c|c|c|c|c|}
\hline \multicolumn{2}{|l|}{ Parameter } & \multirow{2}{*}{$\begin{array}{r}\text { Base case } \\
0.00 \%\end{array}$} & \multirow{2}{*}{$\begin{array}{l}\text { Distribution } \\
\text { type } \\
\text { None }\end{array}$} & \multirow[t]{2}{*}{$\mathbf{A}$} & \multirow[t]{2}{*}{$\bar{\beta}$} & \multirow{2}{*}{$\begin{array}{l}\text { Sources } \\
\text { De Melker (2006) }\end{array}$} \\
\hline HZ mortality & $50-54$ & & & & & \\
\hline & $55-59$ & $0.00 \%$ & None & & & De Melker \\
\hline \multirow[t]{9}{*}{ (monthly) } & $60-64$ & $0.00 \%$ & None & & & De Melker \\
\hline & $65-69$ & $0.00 \%$ & None & & & De Melker \\
\hline & $70-74$ & $0.00 \%$ & None & & & De Melker \\
\hline & $75-79$ & $0.00 \%$ & None & & & De Melker \\
\hline & $80-84$ & $0.00 \%$ & None & & & De Melker \\
\hline & $85-89$ & $0.00 \%$ & None & & & De Melker \\
\hline & $90-94$ & $0.00 \%$ & None & & & De Melker \\
\hline & $95-99$ & $0.00 \%$ & None & & & De Melker \\
\hline & 100 & $0.00 \%$ & None & & & De Melker \\
\hline PHN vaccine & $50-54$ & $0.00 \%$ & None & & & ZEST (see above) \\
\hline \multirow[t]{10}{*}{ efficacy } & $55-59$ & $0.00 \%$ & None & & & ZEST \\
\hline & $60-64$ & $5.00 \%$ & Lognormal & -0.05 & 0.24 & FDA (see above) \\
\hline & $65-69$ & $5.00 \%$ & Lognormal & -0.05 & 0.24 & FDA \\
\hline & $70-74$ & $55.00 \%$ & Lognormal & -0.80 & 0.31 & FDA \\
\hline & $75-79$ & $55.00 \%$ & Lognormal & -0.80 & 0.31 & FDA \\
\hline & $80-84$ & $26.00 \%$ & Lognormal & -0.30 & 0.42 & FDA \\
\hline & $85-89$ & $26.00 \%$ & Lognormal & -0.30 & 0.42 & FDA \\
\hline & $90-94$ & $26.00 \%$ & Lognormal & -0.30 & 0.42 & FDA \\
\hline & $95-99$ & $26.00 \%$ & Lognormal & -0.30 & 0.42 & FDA \\
\hline & 100 & $26.00 \%$ & Lognormal & -0.30 & 0.42 & FDA \\
\hline
\end{tabular}

\section{Results}

The results of the base case scenario (Table 7 below), show that by vaccinating $11 \%$ of the population aged 65 years or more, 544 QALYs would be gained, and 2,512 HZ cases and 925 PHN cases would be prevented.

This corresponds to an ICER of DKK 261,372 or app. €35,000 per QALY (societal perspective) and DKK 268,064 per QALY (Danish Regions' perspective).

The analyses by age groups in Table 8 and Figure 2 below show that vaccinating younger age groups (50 to 70 years old), seems to be slightly more cost-effective than the base case, from the societal perspective. This is mainly because of the productivity gain from the younger persons' not being absent from their work due to $\mathrm{HZ}$ or PHN in the vaccine group, whilst most of the persons above 65 years would have reached retirement and therefore there is only a very small productivity gain in the base case. Alternatively, vaccinating persons aged 70 years or more results in higher cost-effectiveness ratios, especially with for persons aged 80 years or more.

The results of the deterministic sensitivity analysis, shown in Figure 3 (base case population), demonstrate that the results are highly sensitive to changes in assumptions about vaccine price, utility values, discount rates, and particularly - to changes in the duration of vaccine protection.

The cost-effectiveness acceptability curve (Figure 4) produced from the probabilistic analysis simulations shows that when considering a threshold of DKK 263,000 per QALY, the base case scenario is $85 \%$ likely to be cost-effective. For lower societal willingness-topay thresholds, the probability of the vaccine being cost-effective decreases accordingly, and if the willingness-to-pay is even higher, e.g. up to DKK 306,000, the probability of the vaccine being cost-effective increases to $97 \%$. 
Table 7: $\quad$ Base case cost-effectiveness results

\begin{tabular}{|c|c|c|c|}
\hline Results & Lifetime & DK Regions (DKK) & Societal (DKK) \\
\hline \multirow[t]{17}{*}{$\overline{\text { Costs }}$} & Vaccination policy total & DKK 325,083,321 & DKK 381.531.516 \\
\hline & Primary care (GPs) & Same as societal & $63,209,713$ \\
\hline & Secondary care (out-patient specialists) & Same as societal & $14,675,994$ \\
\hline & Medicine not including vaccination costs & Same as societal & $21,601,158$ \\
\hline & Hospitalisation (day cases and in-patient) & Same as societal & $51,467,056$ \\
\hline & Diagnostic tests & Same as societal & $19,559,685$ \\
\hline & Productivity costs & 0 & $56,448,195$ \\
\hline & Vaccination costs & Same as societal & $154,569,714$ \\
\hline & No vaccination policy total & DKK 179,211,200 & DKK 239,300,580 \\
\hline & Primary care (GPs) & Same as societal & $66,991,334$ \\
\hline & Secondary care (out-patient specialists) & Same as societal & $15,565,423$ \\
\hline & Medicine not including vaccination costs & Same as societal & $22,570,245$ \\
\hline & Hospitalisation (day cases and in-patient) & Same as societal & $53,368,824$ \\
\hline & Diagnostic tests & Same as societal & $20,715,374$ \\
\hline & Productivity costs & 0 & $60,089,380$ \\
\hline & Vaccination costs & 0 & 0 \\
\hline & Difference & DKK 145,872,120 & DKK 142,230,244 \\
\hline \multirow[t]{12}{*}{$\overline{\text { Effectiveness }}$} & No. of QALYs & & \\
\hline & Vaccination policy & & $7,734,206$ \\
\hline & No vaccination policy & & $7,733,661$ \\
\hline & Difference - QALYs gained & & 544 \\
\hline & No. of HZ cases & & \\
\hline & Vaccination policy & & 101,177 \\
\hline & No vaccination policy & & 103,689 \\
\hline & Difference - HZ cases avoided & & 2,512 \\
\hline & No. of PHN cases & & \\
\hline & Vaccination policy & & 16,375 \\
\hline & No vaccination policy & & 17,300 \\
\hline & Difference - PHN cases avoided & & 925 \\
\hline \multirow[t]{3}{*}{ ICERs } & Cost per QALY & DKK 268,064 & DKK 261,372 \\
\hline & Cost per HZ case avoided & DKK 58,064 & DKK 56,615 \\
\hline & Cost per PHN case avoided & DKK 157,710 & DKK 153,773 \\
\hline
\end{tabular}


Table 8: Results by age group: Number of cases avoided with vaccination, QALYs gained, costs, incremental cost-effectiveness, and 95\% CI, by age group, (costs in DKK 2011 prices)

\begin{tabular}{|c|c|c|c|c|c|c|c|}
\hline Age Group & $\begin{array}{l}\mathbf{5 0 - 5 4} \\
\text { Years } \\
\end{array}$ & $\begin{array}{l}55-59 \\
\text { years }\end{array}$ & $\begin{array}{l}60-64 \\
\text { years }\end{array}$ & $\begin{array}{l}65-69 \\
\text { years }\end{array}$ & $\begin{array}{l}70-74 \\
\text { years }\end{array}$ & $\begin{array}{l}75-79 \\
\text { years }\end{array}$ & $\begin{array}{l}80-84 \\
\text { years }\end{array}$ \\
\hline $\begin{array}{l}\text { No. of persons in } \\
\text { age group }\end{array}$ & 367,878 & 350,093 & 356,791 & 331,398 & 226,853 & 165,202 & 117,219 \\
\hline $\begin{array}{l}\% \text { vaccination } \\
\text { coverage rate }\end{array}$ & $11 \%$ & $11 \%$ & $11 \%$ & $11 \%$ & $11 \%$ & $11 \%$ & $11 \%$ \\
\hline $\begin{array}{l}\text { No of } \mathrm{HZ} \text { cases } \\
\text { avoided }\end{array}$ & 1,359 & 1,426 & 1,435 & 1,341 & 589 & 400 & 108 \\
\hline $\begin{array}{l}\text { PHN cases avoided } \\
\text { ( } 1 \text { month def.) }\end{array}$ & 395 & 407 & 437 & 417 & 257 & 154 & 60 \\
\hline QALYS gained & 172 & 190 & 219 & 226 & 153 & 98 & 43 \\
\hline $\begin{array}{l}\text { Vaccination } \\
\text { incremental costs, } \\
\text { DKK (Societal) }\end{array}$ & $38,395,750$ & $37,984,782$ & $44,721,308$ & $46,379,172$ & $34,454,576$ & $25,225,154$ & $18,367,685$ \\
\hline $\begin{array}{l}\text { Vaccination } \\
\text { incremental costs, } \\
\text { DKK (Regions) }\end{array}$ & $56,859,563$ & $53,602,986$ & $54.268,955$ & $50,020,366$ & $34,454,576$ & $25,225,154$ & $18,367,685$ \\
\hline $\begin{array}{l}\text { Incremental cost } \\
\text { per QALY gained } \\
\text { (ICER), societal }\end{array}$ & 223,759 & 199,721 & 203,846 & 205,011 & 224,720 & 258,573 & 431,919 \\
\hline ICER 95\% CI & $\begin{array}{l}(54,869- \\
244,592)\end{array}$ & & & & & & \\
\hline $\begin{array}{l}\text { ICER Danish } \\
\text { Regions }\end{array}$ & 331,361 & 281,840 & 247,366 & 221,106 & 224,720 & 258,573 & 431,919 \\
\hline $\begin{array}{l}\text { Cost per HZ case } \\
\text { avoided (societal) }\end{array}$ & 28,246 & 26,641 & 31,159 & 34,585 & 58,507 & 63,034 & 170,111 \\
\hline $\begin{array}{l}\text { Cost per PHN case } \\
\text { avoided (societal) }\end{array}$ & 97,088 & 93,342 & 102,372 & 111,196 & 134,095 & 163,596 & 305,135 \\
\hline
\end{tabular}


Figure 2: ICER by age group

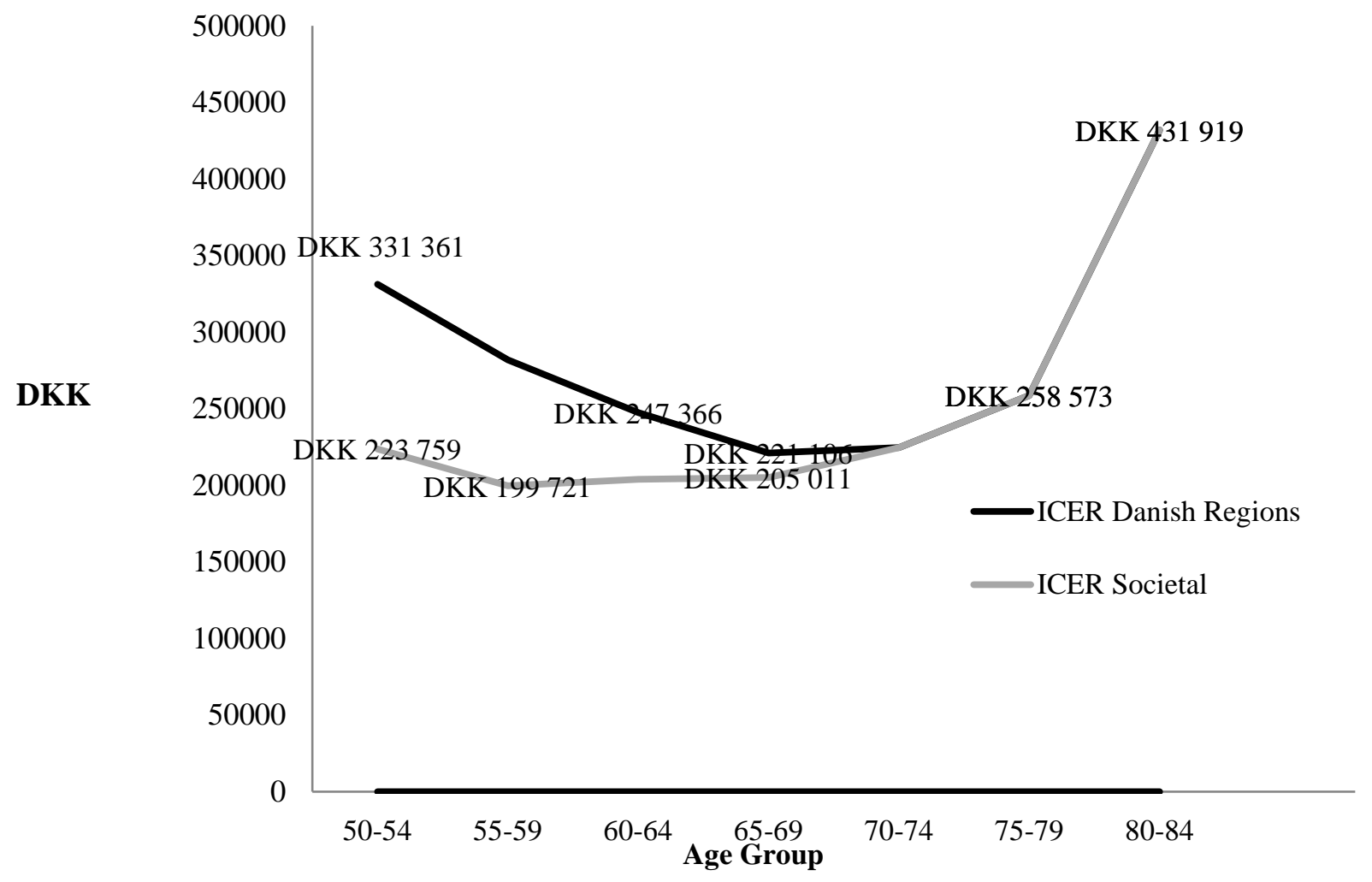

Figure 3: Deterministic sensitivity snalysis, Tornado diagram

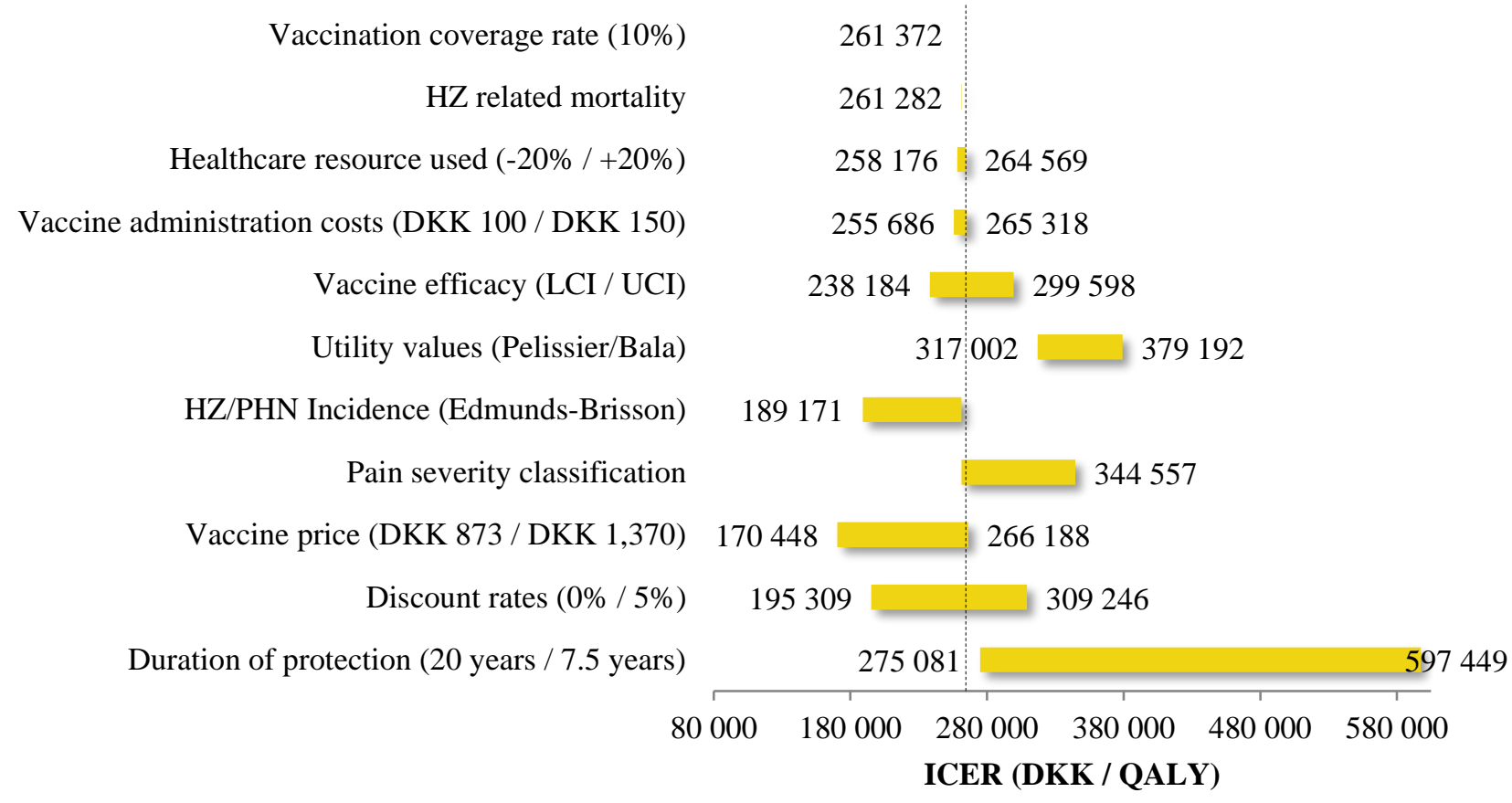




\section{Figure 4: Cost-effectiveness acceptability curve}

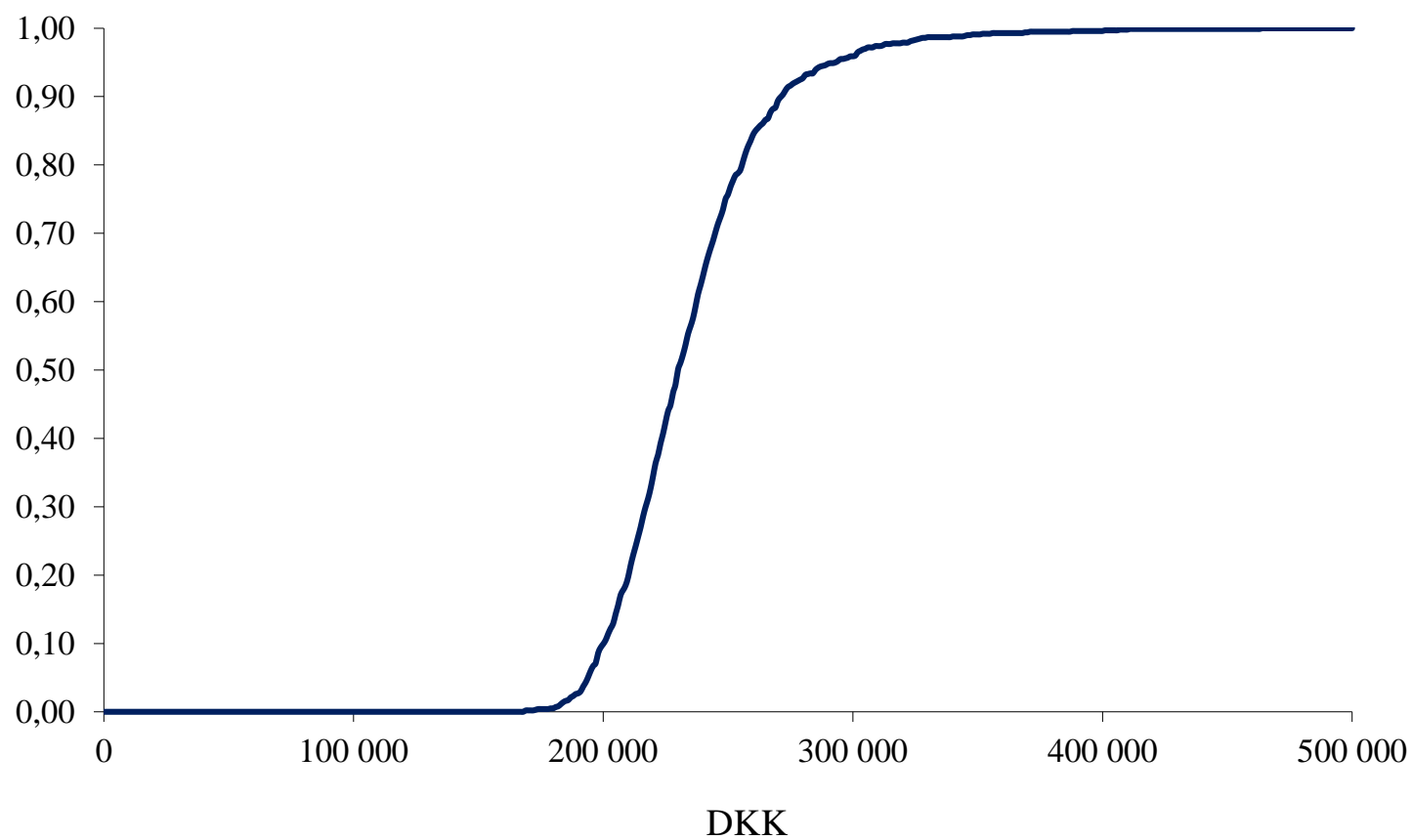

\section{Discussion}

In our base case analysis, we found an incremental cost-effectiveness ratio of DKK 261,372 (societal perspective). The sensitivity analyses show some variation of results when the assumptions are modified. There is no official threshold for the societal willingness to pay for a QALY in Denmark. However, if we assume a threshold equivalent to the informal one applied by NICE in the UK, of $£ 30,000$ (Earnshaw and Lewis, 2008) corresponding to app. DKK 270,000, the ICER of the vaccine in our base case analysis falls below this threshold. Vaccinating younger age-groups than assumed here (e.g. 50-54 years) would provide lower ICERs from the societal perspective, as a more substantial productivity benefit could be harvested, but higher ICERs from the perspective of the Danish Regions. Also, a strategy of vaccinating the persons aged 65 to 69 years only, would result in lower ICERs than the base case, and would therefore seem more cost-effective than the base case strategy.

A number of country-specific studies on the costs and cost-effectiveness of introducing a vaccine against HZ have been published. (Edmunds et al., 2001, Brisson et al., 2008, Moore et al., 2010, Pellissier et al., 2007, van Hoek et al., 2009, Bresse et al., 2013, de Boer et al., 2013, Szucs and Pfeil, 2013, Johnsson et al., 2015). Some of the costeffectiveness studies, e.g. from Moore (UK), Bresse (France), and Szucs (Switzerland) were based on the same generic cost-effectiveness model as the one used for this study. All of the cost-effectiveness studies applied a Markov model to simulate the natural history of HZ and PHN over a lifetime based on known epidemiological features of HZ and PHN and local cost data, although with slightly different assumptions. Our results compare reasonably well with the results of other studies, although most other studies find a lower ICER than ours. In the UK, the decision to implement and reimburse the vaccine was based on the findings of van Hoek et al. (2009) who found an ICER of $£ 20,412$ (approximately DKK 184,000) for vaccinating the UK population of 65 years or more. Although van Hoek et al. used a different cost-effectiveness model than the one used here, their results are comparable to our findings. In the Netherlands, one study (de Boer et al., 2013) simulated the cost- 
effectiveness of vaccinating 60-year olds, and found a societal incremental costeffectiveness ratio (ICER) of $€ 35,555 / \mathrm{Q} A L Y$, (app.DKK 267,000). Another Dutch study (van Lier et al., 2010) resulted in an ICER of €21,716/QALY, (app. DKK 163,000) from the societal perspective, in a cohort of 70-year olds. Furthermore, another UK study (Moore et al., 2010) reported an ICER of $£ 11,417 /$ QALY (app. DKK 102,000) in a cohort of people aged 50 years or more, while Szucs and Pfeil (2011) found that vaccinating Swiss persons aged 70 to 79 years resulted in an ICER of \$26,430/QALY (DKK 153,000). Finally, in a study from France (Bresse et al., 2013), ICERs were estimated at €9,513/QALY and $€ 12,304 / \mathrm{QALY}$ in persons aged 65 years or more and in persons aged 70 to 79 years respectively. These studies naturally differ from our study with regard to assumptions about country-specific costs and epidemiology, and occasionally, with regard to assumptions about utility losses. More importantly, some studies differ with regard to assumptions about the vaccine duration and vaccine waning. Generally, the older studies assume a longer duration of the vaccine in the base case scenario, with a lower annual waning rate, whereas the recent studies have chosen more conservative assumptions about the vaccine duration.

In our base case, we assumed that the protection of the vaccine was reduced by annual (waning) rate of $8.31 \%$ (and $0-8.31 \%$ in the probabilistic sensitivity analysis). The base case assumption corresponds to the upper bound of the $95 \% \mathrm{CI}$ interval $(0-8.31 \%)$ for the waning rate reported by Pellissier et al. (2007). Other cost-effectiveness analyses assumed a lower annual waning rate in their base case analysis, between 0 and $4.15 \%$ (Moore et al., 2010, Pelissier et al., 2007, van Hoek et al., 2009). This may partly explain why their ICERs were generally lower than the ones reported here. As to vaccine waning, our study assumptions seem conservative compared to these studies, and in line the Dutch study from de Boer et al (de Boer et al., 2013) who also assumed $8.31 \%$ annually. However, in our base case we assumed lifetime duration of the vaccine together with the conservative waning rate. In our deterministic sensitivity analysis, we allowed the duration of protection to be lower than lifetime, and found that the results were very sensitive to changes in the duration of protection, e.g. if the duration was assumed to be only 7.5 years, the ICER would increase to almost 600,000 DKK per QALY gained.

It was clear from the sensitivity analysis, that the QALY weights had a significant impact on the results. The base case QALY weights assumed a large decrease in healthrelated quality-of-life in the severe stages of disease (Oster et al., 2005). An analysis based on another cost-effectiveness model by van Hoek et al. (2009) applied the QALY weights results from a fitted model (generalized linear model) based on the EQ5D and VAS results from 11 different studies in similar pain populations. These QALY weights were similar to those of Oster et al. (2005) used in our base case, with very low utility weights for the severe pain stage. However, if we apply a different set of utility weights for $\mathrm{HZ}$ and PHN from other studies (Pellissier et al., 2007, Bala et al.,1998) which use comparable weights for the mild and moderate pain states, but higher weights for the severe state, we find higher ICERs (from 317,000 to DKK 379,000). The studies here discussed have different objectives and use different methods for eliciting the utility values. Oster et al. (2005) use a global rating scale for the respondents' health state as they find the standard gamble method unfit for the self-reported questionnaire in a population-based survey. Van Hoek et al. (2009) gathered the results from other studies in a GLM model. Bala et al., (1998) compared the willingnessto-pay method with EQ5D using the standard gamble method to value the health states, and finally, Pellissier et al. (2007) used a VAS scale. However, the sensitivity of results to QALY estimates is a potential weakness of the analysis.

Another potential weakness of the study is that not all relevant costs are accounted for in the model. Neither patient transportation costs, nor productivity costs from attending health care are included. Also, as most patients in the base-case are 65 year old or more and 
relatively few are in the work force, it may have been appropriate additionally to assign a value to lost leisure from being ill and having to visit various health care providers when being treated for HZ/PHN or being vaccinated. However, no HZ relevant study is available on these types of costs, and valid assumptions about them cannot reasonably be made without individual patient data. Also, it is uncertain whether an inclusion of these costs would have any important bearing on the results, as they would occur for both the intervention and the control group, although they are likely to be higher in the control group who have more episodes of HZ. Furthermore, potential costs relating to the treatment of adverse events from the vaccination are not included in the model. Vaccine safety has been investigated in the SPS study from the day of vaccination to day 42 and in a subsequent study in a subset of the SPS patients, (Oxman et al., 2005). The safety studies showed a higher incidence of injection site-related adverse events in the vaccine group. Vaccinerelated systemic reactions were more frequent in the vaccine group (1.9\% of patients) than in the control group (1.3\% of patients), within the first 42 days from vaccination, whereas no difference was found in the long-term follow-up on severe adverse events (Simberkoff et al., 2015). Assuming that some of the adverse events may require treatment, and/or result in absence from work, it can be argued that the omission of these costs is a major weakness of the analysis, and may have a bearing on the results. However, adverse events are by nature very heterogeneous, some are very rare, and therefore difficult to grasp in a robust cost analysis. In one of the sensitivity analyses, we allowed health care costs to vary by -20 to $+20 \%$. This analysis shows that a change of health care resource use costs only has a minor effect on the ICER results.

The main strength of this study is the ability of the Markov model to describe the progression and consequences of $\mathrm{HZ}$ and PHN, in both the vaccinated and the nonvaccinated population over a lifetime under various assumptions about resource use, vaccine efficacy, and epidemiology. As to the choice of model, for vaccine cost-effectiveness studies, it may be argued that the static Markov model is not sufficiently able to reflect the epidemiology of the vaccinated population e.g. with regard to herd immunity. However, since the vaccine against HZ does not induce herd protection (Johnson et al., 2015), a static model may be appropriate.

\section{Conclusion}

From on our base case analysis, it seems that an implementation of a vaccine against $\mathrm{HZ}$ in Danes aged 65 years or more might be cost-effective from a societal point of view. Also, a strategy of vaccinating from an earlier age, e.g. people aged 50 to 69 years, results in lower ICERs than the base case, seen from the societal perspective. However, these results are highly sensitive to changes in assumptions about price, utility values, discount rates, and especially to the duration of vaccine protection. Assuming higher utility values for the severe pain state than in the base case, as indicated by some studies, results in higher ICERS. However, the most sensitive parameters in the model are the duration of the vaccine protection and waning. In our base case scenario, we assumed lifetime duration with a constant annual waning rate. Changing the duration assumption to a shorter period, e.g. 7.5 years will influence the ICER, and thereby the cost-effectiveness of the vaccine, significantly. More studies into this aspect of the vaccine would therefore be warranted to investigate the potential duration of the vaccine. Finally, the lack of some relevant costs, e.g. patient-related, in the model can be seen as a weakness. However, as these costs will bear on both the vaccinated and non-vaccinated population, the omission of these costs cannot be considered to influence the results in a major way. 


\section{Acknowledgements and conflict of interest}

This study was performed by the Danish Institute for Health Services Research (now merged into KORA - Danish institute for Local and Regional Government Research). L. Bilde, M. Kruse, and T. Nielsen were all employed by the Danish Institute for Health Services Research (DSI) when the analyses were performed. The Danish Institute of Health Services Research received funding from Sanofi Pasteur MSD Denmark for performing the study. All authors declare no conflict of interest.

\section{"Who did what" note}

The generic model was programmed by Optum Insight (now Mapi Values), and was later adapted to the Danish setting for country-specific cost-effectiveness analysis by Marie Kruse and Lone Bilde. Marie Kruse and Lone Bilde also ran the various analyses in the model and drafted the paper versions. Thomas T. Nielsen has assisted in the collection of Danish data, calculated the unit costs, and imputed values in the model. Finn Rønholt has provided the clinical perspective on the analysis and the Danish model. All authors have read and commented on paper drafts.

\section{References}

Ankjær-Jensen, A., Rosling, P. \& Bilde, L. (2006). Variable prospective financing in the Danish hospital sector and the development of a Danish case-mix system, Health care management science, 9 (3), 259-268. 30(5), 880-893.

Bala, M.V., Wood, L.L., Zarkin, G.A., Norton, E.C., Gafni, A. \& O’Brien, B. (1998), Valuing outcomes in health care: a comparison of willingness to pay and quality-adjusted life-years, Journal of clinical epidemiology, 51 (8), 667-676.

Bresse, X., Annemans, L., Preaud, E., Bloch, K., Duru, G. \& Gauthier, A. (2013), Vaccination against herpes zoster and postherpetic neuralgia in France: a cost-effectiveness analysis, Expert Reviews, 13 (3),1473.

Brisson, M., Pellissier, J.M., Camden, S., Quach, C. \& De Wals, P. (2008), The potential costeffectiveness of vaccination against herpes zoster and post-herpetic neuralgia, Human vaccines, 4 (3), 238-245.

CVZ Health Insurance Board, (the Netherlands) \& University Hospital, A. Gemilli (Italy) (2013), Zostavax for the prevention of herpes zoster and postherpetic neuralgia. Pilot assessment using the draft HTA core model for rapid relative effectiveness assessment. EUnetHTA WP5 Joint Action 2 Strand A. v 4.0 Final Version, EUnetHTA, Denmark.

DADL 2012, Overenskomsten FAPS. Available: http://www.laeger.dk/portal/pls/portal/!POR TAL.wwpob_page.show?_docname=8054864.PDF [2013, . Accessed 13 June 2013]

de Boer, P.T., Pouwels, K.B., Cox, J.M., Hak, E., Wilschut, J.C. \& Postma, M.J. (2013), Costeffectiveness of vaccination of the elderly against herpes zoster in The Netherlands, Vaccine, 31(9), 1276-1283.

de Melker, H., Berbers, G., Hahne, S., Rumke, H., van den Hof, S., de Wit, A. \& Boot, H. (2006), The epidemiology of varicella and herpes zoster in The Netherlands: implications for varicella zoster virus vaccination, Vaccine, 24 (18), 3946-3952.

Drummond, M.F., Sculpher, M.J. \& Torrance, G.W. (2005), Methods for the economic evaluation of health care programs, Oxford university press.

Earnshaw, J. \& Lewis, G. (2008), NICE Guide to the Methods of Technology Appraisal, PharmacoEconomics, 26 (9), 725-727. 
Edmunds, W., Brisson, M. \& Rose, J. (2001), The epidemiology of herpes zoster and potential costeffectiveness of vaccination in England and Wales, Vaccine, 19 (23), 3076-3090.

Gauthier, A., Breuer, J., Carrington, D., Martin, M. \& Rémy, V. (2009), Epidemiology and cost of herpes zoster and post-herpetic neuralgia in the United Kingdom, Epidemiology and infection, 137(1), 38.

Gialloreti, L., Merito, M., Pezzotti, P., Naldi, L., Gatti, A., Beillat, M., Serradell, L., di Marzo, R. \& Volpi, A. (2010), Epidemiology and economic burden of herpes zoster and post-herpetic neuralgia in Italy: a retrospective, population-based study, BMC infectious diseases, 10(1), 230.

Johnson RW, Alvarez-Pasquin M, Bijl M, Franco E, Gaillat J, Clara JG, Labetoulle M, Michel JP, Naldi L, Sanmarti LS, Weinke T (2015), Herpes zoster epidemiology, management, and disease and economic burden in Europe, a multidisciplinary perspective, Therapeutic advances in vaccines, 3(4),109-120.

McDermott AM, Toelle TR, Rowbotham DJ, Schaefter CP, Dukes EM. (2006), The burden of neuropathic pain: results from a cross-sectional survey European Journal of Pain; 10(2), 127 135.

Moore, L., Remy, V., Martin, M., Beillat, M. \& McGuire, A. (2010), A health economic model for evaluating a vaccine for the prevention of herpes zoster and post-herpetic neuralgia in the UK, Cost effectiveness and resource allocation, 8(1), 7.

Opstelten, W., Mauritz, J.W., de Wit, N.J., van Wijck, A.J., Stalman, W.A. \& van Essen, G.A. (2002), Herpes zoster and postherpetic neuralgia: incidence and risk indicators using a general practice research database, Family practice, 19 (5), 471-475.

Oster, G., Harding, G., Dukes, E., Edelsberg, J. \& Cleary, P.D. (2005), Pain, medication use, and health-related quality of life in older persons with postherpetic neuralgia: results from a population-based survey, The journal of pain : official journal of the American Pain Society, 6 (6), 356-363.

Oxman, M., Levin, M., Johnson, G., Schmader, K., Straus, S., Gelb, L., Arbeit, R., Simberkoff, M., Gershon, A. \& Davis, L. (2005), A vaccine to prevent herpes zoster and postherpetic neuralgia in older adults, New England Journal of Medicine, 352 (22), 2271-2284.

Pellissier, J.M., Brisson, M. \& Levin, M.J. (2007), Evaluation of the cost-effectiveness in the United States of a vaccine to prevent herpes zoster and postherpetic neuralgia in older adults, Vaccine, 25 (49), 8326-8337.

Pinchinat, S., Cebrian-Cuenca, A.M., Bricout, H. \& Johnson, R.W. (2013), Similar herpes zoster incidence across Europe: results from a systematic literature review, BMC infectious diseases, 13 (170), 1471.

Sanofi Pasteur MSD (2009), ZAP pro: Zoster i Almen Praksis. Prospektivt klinisk epidemiologisk studie om herpes zoster og postherpetisk neuralgi (27-01-2009). Upublished, Sanofi Pasteur MSD, [U.st].

Schiffner-Rohe, J., Jow, S., Lilie, H.M., Koster, I. \& Schubert, I. (2010), Herpes zoster in Germany. A retrospective analysis of SHL data, MMW Fortschritte der Medizin, 151 (Suppl 4), 193-197.

Schmader, K., Levin, M.J., Gnann Jr, J.W., McNeil, S.A., Vesikari, T., Betts, R.F., Keay, S., Stek, J.E., Bundick, N.D., Su, S., Zhao, Y., Li, X., Chan, I.S.F., Annunziato, P.W. \& Parrino, J. (2012), Efficacy, safety, and tolerability of herpes zoster vaccine in persons aged 50-59 years, Clinical infectious diseases, 54(7), 922.

Simberkoff , M.S., Arbeit, R.D., Johnson G.R., Oxman M.N., Boardman K.D., Williams H.M., Levin M.J., Schmader, .K.E., Gelb, L.D., Keay S., Neuzil K., Greenberg R.N., Griffin, M.R., Davis, L.E., Morrison, V.A. \& Annunziato P.W, for the Shingles Prevention Study, (2010), Safety of herpes zoster vaccine in the Shingles Prevention Study, Annals of Internal Medicine, $152(9), 545-554$. 
Statens Serum Institut (2013), Sæsoninfluenza-vaccination (aldersgruppe), vaccinationstilslutning. Available:

http://www.ssi.dk/Smitteberedskab/Sygdomsovervaagning/VaccinationSurveillance.aspx?vac cination $=14 \&$ season $=2009 \mid 2012 \&$ se $=3 \&$ agegroup $=10 \&$ landsdel $=100 \&$ kommune $=1000 \& x a$ xis $=$ AgeGroup $\&$ yaxis $=$ Season $\&$ show $=$ Table $\&$ datatype $=$ Vaccination\#HeaderText.

Stinnett, A.A. \& Mullahy, J. (1998), Net health benefits: a new framework for the analysis of uncertainty in cost-effectiveness analysis, Medical Decision Making, 18 (Suppl.2), 68-80.

Szucs, T.D. \& Pfeil, A.M. (2013), A systematic review of the cost effectiveness of herpes zoster vaccination, PharmacoEconomics, 31 (2), 125-136.

Szucs, T.D., Kressig, R.W., Papageorgiou, M., Kempf, W., Michel, J., Fendl, A. \& Bresse, X. (2011), Economic evaluation of a vaccine for the prevention of herpes zoster and post-herpetic neuralgia in older adults in Switzerland, Human vaccines, 7(7), 749-756.

van Hoek, A.J., Gay, N., Melegaro, A., Opstelten, W. \& Edmunds, W.J. (2009), Estimating the costeffectiveness of vaccination against herpes zoster in England and Wales, Vaccine, 27 (9), 14541467.

van Lier, A., van Hoek, A.J., Opstelten, W., Boot, H.J. \& de Melker, H.E. (2010), Assessing the potential effects and cost-effectiveness of programmatic herpes zoster vaccination of elderly in the Netherlands, BMC health services research, 10, 237.

Østergaard, K., Damgaard, M., Birk Kristensen, T. \& Gregaard Madsen, K. (2009), Incidens af herpes zoster hos personer over 50 år, Ugeskrift for lager, 171(26-32), 2194-2197.

(C) 2016 by the author(s). This article is an open access article distributed under the terms and conditions of the Creative Commons Attribution license (http://creativecommons.org/licenses/by/4.0/). 